\title{
Synthesis of Silver-Doped Zinc Oxide Nanocomposite by Pulse Mode Ultrasonication and Its Characterization Studies
}

\author{
T. Siva Vijayakumar, ${ }^{1}$ S. Karthikeyeni, ${ }^{1}$ S. Vasanth, ${ }^{1}$ Arul Ganesh, ${ }^{1}$ G. Bupesh, ${ }^{2}$ \\ R. Ramesh, ${ }^{1}$ M. Manimegalai, ${ }^{3}$ and P. Subramanian ${ }^{1}$ \\ ${ }^{1}$ Department of Animal Science, Bharathidasan University, Trichy 620024, India \\ ${ }^{2}$ Department of Virology, King's Institute of Preventive Medicine, Guindy, Chennai 600032, India \\ ${ }^{3}$ Department of Zoology, Seethalakshmi Ramaswami College, Trichy 620002, India
}

Correspondence should be addressed to P. Subramanian; subbus1952@gmail.com

Received 23 April 2013; Revised 8 July 2013; Accepted 30 July 2013

Academic Editor: Oleg I. Lupan

Copyright (C) 2013 T. Siva Vijayakumar et al. This is an open access article distributed under the Creative Commons Attribution License, which permits unrestricted use, distribution, and reproduction in any medium, provided the original work is properly cited.

\begin{abstract}
The synthesis of silver-doped zinc oxide (Ag: $\mathrm{ZnO})$ nanocomposite material was achieved using a simple chemical coprecipitation method, in which $0.2 \mathrm{M}$ zinc chloride and $0.001 \mathrm{M}$ silver nitrate coprecipitated with $25 \%$ ammonia solution by pulse mode dispersion using ultrasonicator. The obtained silvery white precipitate was dried overnight at $110^{\circ} \mathrm{C}$ in hot air oven, and the powder was collected. The resulted Ag: $\mathrm{ZnO}$ nanocomposite was structurally and optically characterized using various techniques. The $\mathrm{X}$ ray diffraction (XRD) pattern clearly showed the presence of crystalline Ag:ZnO particles. Further, UV-Vis spectrophotometer and fourier transform infrared spectroscopy (FT-IR) results showed the presence of Ag:ZnO nanocomposite at specific wavelengths. The scanning electron microscopy (SEM) and transmission electron microscopy (TEM) analysis confirm that the synthesized Ag:ZnO nanocomposite material was truncated nanorod in shape and has 48 to $226 \mathrm{~nm}$ size in diameter.
\end{abstract}

\section{Introduction}

Zinc oxide $(\mathrm{ZnO})$ is an important industrial material, because it has an inorganic and semiconducting material with inherent properties that share its structure as wurtzite [1]. $\mathrm{ZnO}$ nanocomposite has attracted interest because of its optical properties. These particles are transparent to visible light, but they absorb UV-light. $\mathrm{ZnO}$ has attracted intensive research effort for its unique properties and versatile applications in transparent electronics, chemical sensors, and spin electronics [2-8]. A variety of metal oxides like zinc oxide, titanium dioxide $\left(\mathrm{TiO}_{2}\right)$, and silicon dioxide $\left(\mathrm{SiO}_{2}\right)$ and different techniques such as chemical coprecipitation $[9,10]$, sol-gel process [11, 12] chemical vapour deposition [13], thermal decomposition $[14,15]$, hydrothermal synthesis [16, 17], solidstate reaction [18], spray pyrolysis [19], vapour-liquid-solid method [20], and microemulsion precipitation [21-23] have been used so far. Hingorani et al. also reported the synthesis of $\mathrm{ZnO}$ nanoparticles (NPs) and it was the first study using reverse microemulsion in the early 1990s [24, 25].
Synthesis process of Ag: $\mathrm{ZnO}$ nanocomposite plays a key role in governing size, morphology, and its properties of nanocomposite through dispersion method (pulse mode), using ultrasonication [26]. The main objective of synthesis is to produce particles only in nanorod structure for various toxicity and biological application studies. There are different doping agents like P [27], N [28], As [29], Li [30], Sb [3134], and Ag [35]. Among these, we have taken Ag as doping agent. Because the nature of Ag ions is simple link matrices, their behaviour to surface states in nanomaterials where the surfaces of are becomes prime importance as the size decreases. The sonochemical synthesis of nanomaterial is extensively used to generate novel materials with different properties, because this method can produce similar truncated nanorods with smaller size than those reported by other methods [36-38]. The advantages of chemical coprecipitation method through sol-gel process for preparing nanocomposite materials are to get small average particle size and narrow size distribution, homogeneity, purity, and more possibility to obtain nanorods. 


\section{Materials and Methods}

All chemicals used in this study (zinc chloride $98 \%$, silver nitrate $99.8 \%$, and ammonia 25\%) were AR grade purchased from HiMedia, Mumbai, India. All reagents were prepared by using deionised water (18 $\mathrm{M} \Omega$ resistivity).

2.1. Synthesis of Ag-Doped $\mathrm{ZnO}$ Nanocomposite. $0.2 \mathrm{M}$ zinc chloride $\left(\mathrm{ZnCl}_{2}\right)$ and $0.001 \mathrm{M}$ silver nitrate $\left(\mathrm{AgNO}_{3}\right)$ were mixed to $50 \mathrm{~mL}$ of distilled water. A $2 \mathrm{~mL}$ of $25 \%$ ammonia solution was added dropwise until precipitation occurred, and then further 10 drops of ammonia solution $\left(\mathrm{NH}_{4} \mathrm{OH}\right)$ were added to make the solution clear. Pulse mode sonication (PS) was operated at $112.5 \mathrm{~W}$, and the frequency of the sonicator were maintained at $20 \mathrm{kHz} \pm 50 \mathrm{~Hz}$. PS takes place for one second then stops for one second, and the total process took two hours to get precipitates. The initial $\mathrm{pH}$ of the solution was 10.2 , whereas at the end, the $\mathrm{pH}$ was 8.2 and the solution became clear silvery white, and gradually solid suspension is settled. The formed precipitate was washed several times with deionised water and acetone followed by centrifugation at $3500 \mathrm{rpm}$ for the complete elimination of chloride. The precipitate was then dried at room temperature and kept overnight inside an oven at $110^{\circ} \mathrm{C}$ in atmospheric pressure to obtain dry powder.

Ammonia solution $\left(\mathrm{NH}_{4} \mathrm{OH}\right)$ was used as precipitating agent during synthesis between zinc chloride $\left(\mathrm{ZnCl}_{2}\right)$ and silver nitrate $\left(\mathrm{AgNO}_{3}\right)$ with water $\left(\mathrm{H}_{2} \mathrm{O}\right)$ to form $\mathrm{Zn}(\mathrm{OH})_{2}$, $\mathrm{AgOH}, \mathrm{NH}_{4} \mathrm{Cl}, \mathrm{NH}_{4} \mathrm{NO}_{3}$, and $\mathrm{H}_{2} \mathrm{O}$. The product was washed with deionised water for several times to form $\mathrm{Zn}(\mathrm{OH})_{2}$, $\mathrm{AgOH}$, and $\mathrm{H}_{2} \mathrm{O}$, then again washed with acetone by centrifuging in order to form $\mathrm{Zn}(\mathrm{OH})_{2}$ and $2 \mathrm{AgOH}$. On heating at $110^{\circ} \mathrm{C}$ the product obtained was pure $\mathrm{ZnO}$-doped $\mathrm{Ag}_{2} \mathrm{O}$ like ( $\mathrm{Zn}-\mathrm{O}-\mathrm{Ag})$ in the precursor. Through the solvothermal process, the precursor reduced by acetone gradually and $\mathrm{Zn}-\mathrm{O}-$ $\mathrm{Ag}$ bond formation between $\mathrm{Ag}$-doped $\mathrm{ZnO}$ nanocomposite materials, which has been explained as

$$
\begin{aligned}
\mathrm{ZnCl}_{2} & +\mathrm{AgNO}_{3}+\mathrm{NH}_{4} \mathrm{OH}+\mathrm{H}_{2} \mathrm{O} \\
\longrightarrow & \mathrm{Zn}(\mathrm{OH})_{2}+\mathrm{AgOH}+\mathrm{NH}_{4} \mathrm{Cl}+\mathrm{NH}_{4} \mathrm{NO}_{3} \\
& +\mathrm{H}_{2} \mathrm{O} \quad \text { (Wash with } \mathrm{DD} \mathrm{H}_{2} \mathrm{O} \text { (3 times)) } \\
\mathrm{Zn}(\mathrm{OH})_{2} & +\mathrm{AgOH}+\mathrm{H}_{2} \mathrm{O} \quad \text { (Wash with Acetone) } \\
\longrightarrow & \mathrm{Zn}(\mathrm{OH})_{2}+2 \mathrm{AgOH} \underset{110^{\circ} \mathrm{C}}{\stackrel{\Delta}{\longrightarrow}} \mathrm{ZnO}+\mathrm{Ag}_{2} \mathrm{O}+\mathrm{H}_{2} \mathrm{O} \uparrow
\end{aligned}
$$

\subsection{Characterization of Ag: $\mathrm{ZnO}$ Nanocomposite Material.} Several techniques were used to characterize Ag: $\mathrm{ZnO}$ nanocomposite material like UV-Visible spectroscopy, XRD and FT-IR. The crystalline nature of nanocomposite was characterized by XRD, using PANalytical Xpert-Pro diffractometer equipped with $\mathrm{Cu} \mathrm{K} \alpha$ radiation $(\lambda=1.5406 \AA)$. Morphology of the sample was studied by using SEM (Model FEG-Nova 600 Nano SEM). The UV-Vis spectra were recorded with multimode microplate reader (Synergy HT) in the wavelength range between 300 and $800 \mathrm{~nm}$. An FT-IR spectrum was recorded using Perkin-Elmer instrument (model spectrum $\mathrm{RX}_{1}$ ). Further Ag: $\mathrm{ZnO}$ nanocomposite material was characterized by using various techniques like DLS and TEM.

\section{Results and Discussion}

This work reports that the synthesis of Ag-doped $\mathrm{ZnO}$ nanocomposite material through chemical coprecipitation method overpoweringly achieves the synthesis through pulse mode dispersion by ultrasonication. In this study, it was clearly observed that the catalyst ammonia plays a primary role in forming the shape of a particle during the synthesis process. Moreover, the shape of the nanocomposite changed to rod from spheres when it was doped with silver ions, and it was an interesting morphology observed through TEM analysis. Most of the reports were about silver and gold nanocomposite $[39,40]$, but only a few data were available for doping of wide band semiconductor like $\mathrm{ZnO}$ with silver ions. The comprehensive structural studies are not available, and the methods of preparation of doped NPs are still evolving $[41,42]$. In the synthesis method, $\mathrm{pH}$ also plays an important role in the formation of diverse morphology [43].

3.1. X-Ray Diffraction Study. The average crystallite size can be determined through Full Width at Half Maximum (FWHM) of X-ray diffraction peak by using Debye-Scherer's equation as

$$
I=\frac{0.9 \lambda}{\beta \cos \theta},
$$

where $I$ is grain size (nm), $\lambda$ is wavelength of the XRD used, $\beta$ is FWHM, and $\theta$ is Bragg's angle. X-ray diffractogram was analyzed to obtain information about various crystalline aspects of $\mathrm{Ag}: \mathrm{ZnO}$ nanocomposite material. The Xray diffraction patterns of $\mathrm{Ag}: \mathrm{ZnO}$ nanocomposite material are wurtzite hexagonal phase [44] and were shown in Figure 1 which indicates the well-indexed XRD peaks corresponding to the planes (100), (002), and (101), JCPDS no. 89-1397. The peak (103) indicates the presence of silver (Ag), and no other impurities were observed (the standard file of JCPDS no. 893722). These results indicate that the products consisted of pure phases. Furthermore, the diffraction peaks were more intensive and narrower, implying a good crystalline nature of Ag: $\mathrm{ZnO}$ nanocomposite products. The size range of $\mathrm{Ag}: \mathrm{ZnO}$ nanocomposite material was from $26 \mathrm{~nm}$ to $136 \mathrm{~nm}$ in diameter according to Debye-Scherer's equation.

3.2. Fourier Transform Infrared Spectroscopy Study. Synthesized Ag:ZnO nanocomposite material was analysed by FTIR in the range from 400 to $4000 \mathrm{~cm}^{-1}$ at room temperature (Figure 2). The FT-IR spectrum of the Ag: $\mathrm{ZnO}$ nanocomposite material contains several bands with remarkable features. The bands between 400 and $750 \mathrm{~cm}^{-1}$ correlated to metal oxide bond $(\mathrm{ZnO})$ [45-47]. Bands around $900-1500 \mathrm{~cm}^{-1}$ are due to the oxygen stretching and bending frequency $[48,49]$. The spectral band at $463.01 \mathrm{~cm}^{-1}$ and band at $723.96 \mathrm{~cm}^{-1}$ clearly show the presence of $\mathrm{ZnO}$ and $\mathrm{Ag}$ ions approximately 


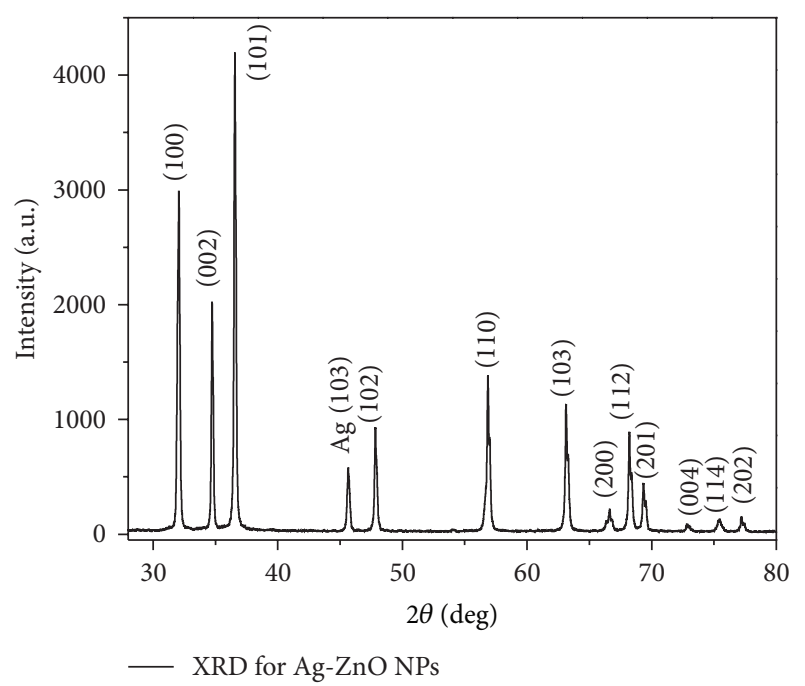

FIGURE 1: XRD pattern of synthesised Ag:ZnO nanocomposite material.

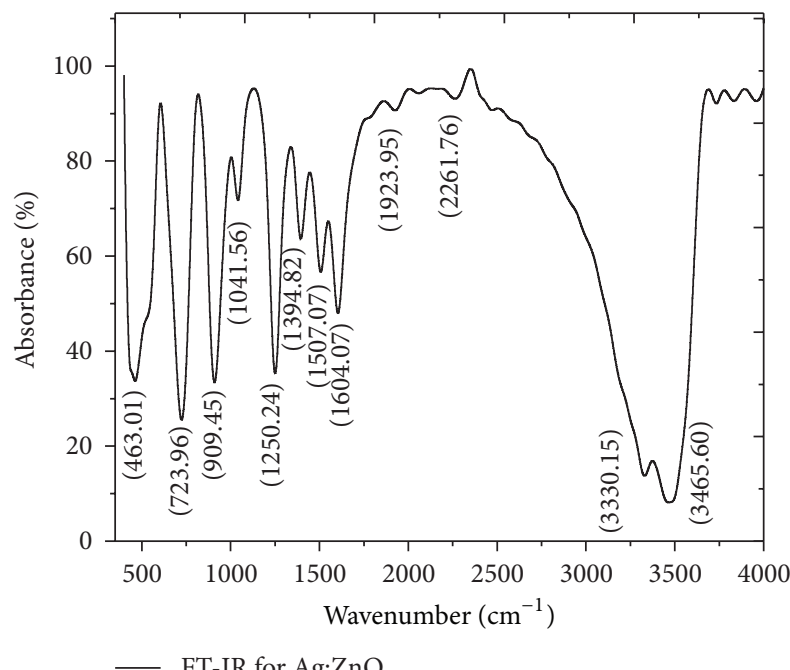

FIGURE 2: FT-IR spectra of Ag:ZnO nanocomposite material.

equal to those reported in the literature [50]. On doping, stronger and wider absorption were bands observed in the region $\sim 723.96 \mathrm{~cm}^{-1}$ due to the organic capping of silver [51]. Bands at $1394.82 \mathrm{~cm}^{-1}$ and $1507.07 \mathrm{~cm}^{-1}$ correspond to $\mathrm{C}=\mathrm{O}$ and $\mathrm{O}-\mathrm{H}$ bending vibrations, respectively. The presence of weak band near $1604.07 \mathrm{~cm}^{-1}$ is assigned to $\mathrm{H}-\mathrm{O}-\mathrm{H}$ bending may due to the adsorption of moisture. Bands at $3465.60 \mathrm{~cm}^{-1}$ indicate the presence of $\mathrm{OH}$ group. It is evident from the FTIR data that the $\mathrm{Zn}-\mathrm{O}$ vibrational mode was more prominently observed, and this clearly concludes a strong doping between $\mathrm{Ag}$ and $\mathrm{ZnO}$ nanocomposite materials [52].

3.3. UV-Visible Absorption Study. The UV-Vis absorption spectra (Figure 3) of Ag: $\mathrm{ZnO}$ nanocomposite material were

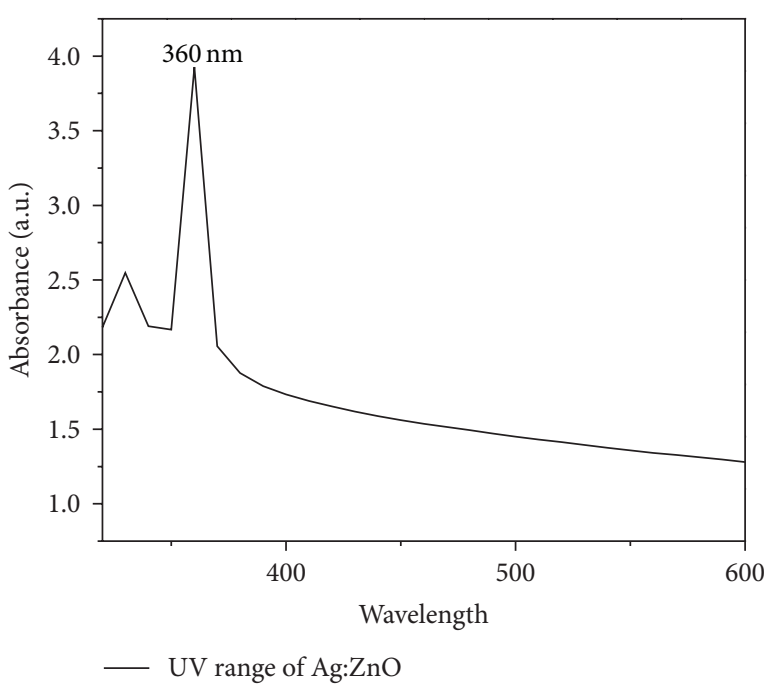

FIGURE 3: UV-Vis absorption spectra of Ag:ZnO nanocomposite material.

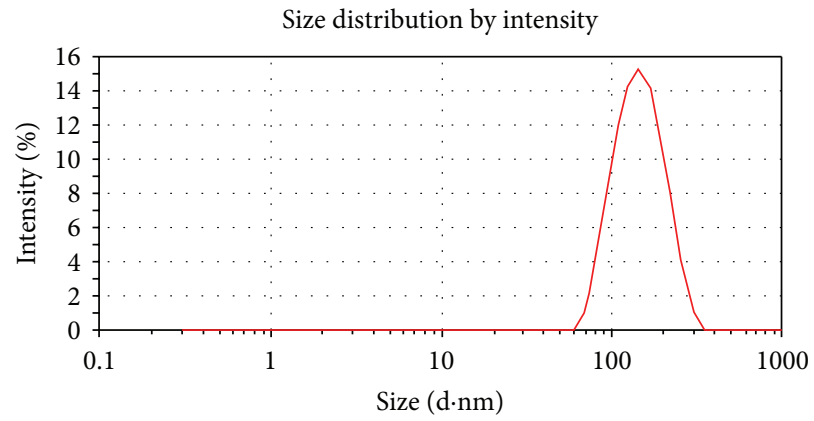

Figure 4: Dynamic light scattering pattern of the Ag: $\mathrm{ZnO}$ nanocomposite material.

recorded at room temperature. The synthesized nanocomposites were dispersed in ethanol with the concentration of $0.1 \%$ water, and the solution was used to record UV-Vis spectra at wavelength range between 300 and $600 \mathrm{~nm}$. The spectra reveal a characteristic absorption peak of Ag: $\mathrm{ZnO}$ nanocomposite material at $360 \mathrm{~nm}[53,54]$. The absorbance increases in the higher wavelength side indicating the role of nano $\mathrm{Ag}$ particles in $\mathrm{ZnO}$. More numbers of $\mathrm{Ag}$ are dispersed into $\mathrm{ZnO}$, and these metallic particles rest on the surface of $\mathrm{ZnO}$ nanocomposite making the surface area increased and showing plasmonic resonance peak in the UV-Vis spectra. This is an important method in which $\mathrm{Ag}: \mathrm{ZnO}$ composite nanorod has been shown and elevated by UV absorption. This high absorbance of the Ag: $\mathrm{ZnO}$ composite nanorods has an important implication for various industrial applications.

3.4. DLS Study. Malvern particle size analyzer (Model, Micro-P) was used to measure the size of synthesized Ag: $\mathrm{ZnO}$ nanocomposite materials. The average size obtained by the DLS distribution plot was around 60 to $300 \mathrm{~nm}$, in this $163 \mathrm{~nm}$ particles were more (Figure 4). The dimension of Ag-doped 


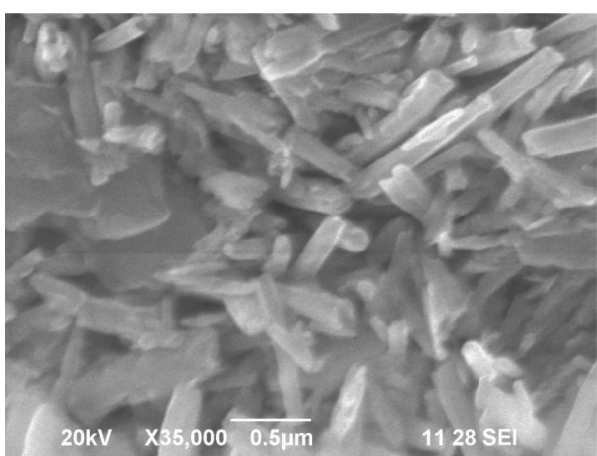

(a)

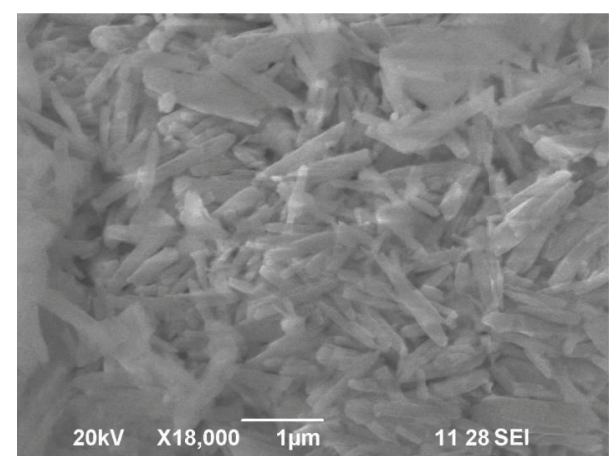

(b)

FIGURE 5: SEM micrograph of (a) $0.5 \mu \mathrm{m}$ resolution image and (b) $1 \mu \mathrm{m}$ resolution image of the truncated nanorod of Ag: $\mathrm{ZnO}$.

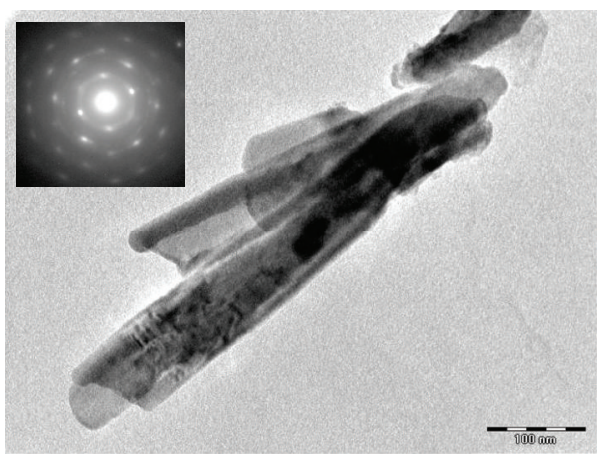

(a)

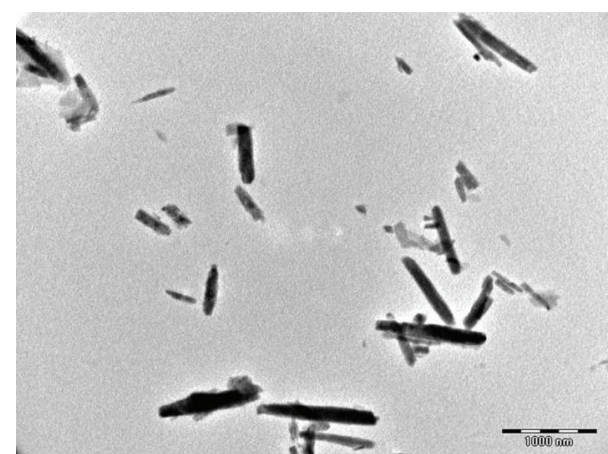

(b)

FIGURE 6: TEM micrograph of (a) single nanorod at high resolution (100 nm) along with (SAED) arrangement and (b) multiple truncated nanorods of $\mathrm{Ag}: \mathrm{ZnO}$ at $1000 \mathrm{~nm}$.

zinc oxide averages in the form of an equivalent sphere and hence does not give the distribution in the range of lengths or widths of the nanorods. The average sizes from DLS result that the particle also coincide with SEM and TEM results [55].

3.5. SEM and TEM Analyses of the Ag:ZnO Nanocomposite Materials. The SEM uses a focused beam of higher energy electrons to generate a variety of signals at the surface of solid specimens. The signals that derive from electron sample interactions reveal information about the sample including external morphology. When samples were viewed under SEM, the truncated nanorod morphology with irregular size was observed, which was randomly orientated. The diameter and length of the Ag-doped zinc oxide nanorod were found, approximately 54 to $226 \mathrm{~nm}$ diameters and from 601 to $1420 \mathrm{~nm}$ length with one-dimension were segregated (Figures $5(\mathrm{a})$ and $5(\mathrm{~b}))$.

TEM characterization was carried out in diffraction and imaging modes by using FEI-TECNAI G2-20 working at $200 \mathrm{KV}$. Images of Ag:ZnO NPs shown in Figures 6(a) and 6(b) are monodisperse, and the selected area diffraction (SAED) pattern apparently showed clear truncated nanorod structure of the nanocomposite. From the TEM micrograph, the diameter of Ag-doped zinc oxide was found to be approximately 48 to $126 \mathrm{~nm}$ and the length was 232 to $1255 \mathrm{~nm}$ with one-dimension of nanorod. The doping of silver with zinc oxide nanocomposite material changes spherical $\mathrm{ZnO}$ to rod shape Ag: $\mathrm{ZnO}$ particles. The entire particle sizes results obtained were almost the same in XRD, DLS, SEM, and TEM when comparing with one another. Finally, The shape and size of the Ag: $\mathrm{ZnO}$ nanocomposite was confirmed by the comprehensible techniques such as SEM and TEM.

\section{Conclusions}

From the above presented experimental results and discussion, it is clear that the synthesis through ultrasonication method gives the following conclusions.

(a) Chemical Coprecipitation is an easy and simple method that played an efficient task in the synthesis of $\mathrm{Ag}: \mathrm{ZnO}$ nanocomposite material when compared with other methods.

(b) In pulse mode synthesis, precursor and reducing agent are main reasons for the morphological changes during synthesis.

(c) Addition of $\mathrm{Ag}^{+}$ions during dispersion (Pulse mode) through ultrasonication increases high crystalline nature and change in morphology. 
(d) $\mathrm{Ag}^{+}$ion rests upon the surface of the zinc oxide at some stage to form truncated nanorod morphology.

(e) Temperature, time, and alteration of initial and final $\mathrm{pH}$ also play prominent role in forming different size and morphological evolution of Ag-doped zinc oxide nanocomposite (Ag: $\mathrm{ZnO})$.

Finally, it was concluded that the several unique features of synthesized Ag: $\mathrm{ZnO}$ were observed with the deserved special comments. The generality and simplicity for the synthesis of Ag-doped $\mathrm{ZnO}$ nanocomposite material are involved in trouble-free steps. Several researchers have recently reported the chemical coprecipitation synthesis of nanocomposite, nanowires, and nanorods [56-59]. However, our chemical coprecipitation method allows the synthesis of nanorods in easy way where the dispersion method by ultrasonicator plays novelty in the formation of nanorod Ag: $\mathrm{ZnO}$.

\section{Acknowledgments}

The authors owe sincere thanks to UGC and UGC-RFSMS for providing financial support and MoE\&F for providing instrumentation facility. The authors thank Dr. N. P. Lalla UGC-DAE CSR Indore for TEM measurement that is highly appreciable and commendable. Sincere thanks are to Department of Chemistry and Physics, Bharathidasan University, Tiruchirappalli, for their valuable suggestions and comments.

\section{References}

[1] Y. K. Mishra, V. S. K. Chakravadhanula, V. Hrkac et al., "Crystal growth behaviour in $\mathrm{Au}-\mathrm{ZnO}$ nanocomposite under different annealing environments and photoswitchability," Journal of Applied Physics, vol. 112, Article ID 064308, 2012.

[2] K. Nomura, H. Ohta, K. Ueda, T. Kamiya, M. Hirano, and H. Hosono, "Thin-film transistor fabricated in single-crystalline transparent oxide semiconductor," Science, vol. 300, no. 5623, pp. 1269-1272, 2003.

[3] S. Y. Lee, E. S. Shim, H. S. Kang, S. S. Pang, and J. S. Kang, "Fabrication of $\mathrm{ZnO}$ thin film diode using laser annealing," Thin Solid Films, vol. 473, no. 1, pp. 31-34, 2005.

[4] R. Könenkamp, R. C. Word, and C. Schlegel, "Vertical nanowire light-emitting diode," Applied Physics Letters, vol. 85, no. 24, pp. 6004-6006, 2004.

[5] Z. L. Wang, X. Y. Kong, Y. Ding et al., "Semiconducting and piezoelectric oxide nanostructures induced by polar surfaces," Advanced Functional Materials, vol. 14, no. 10, pp. 943-956, 2004.

[6] Y. Ushio, M. Miyayama, and H. Yanagida, "Effects of interface states on gas-sensing properties of a $\mathrm{CuO} / \mathrm{ZnO}$ thin-film heterojunction," Sensors and Actuators B, vol. 17, no. 3, pp. 221226, 1994.

[7] H. Harima, "Raman studies on spintronics materials based on wide bandgap semiconductors," Journal of Physics Condensed Matter, vol. 16, no. 48, pp. S5653-S5660, 2004.

[8] S. J. Pearton, W. H. Heo, M. Ivill, D. P. Norton, and T. Steiner, "Dilute magnetic semiconducting oxides," Semiconductor Science and Technology, vol. 19, no. 10, pp. R59-R74, 2004.
[9] L. Wang and M. Muhammed, "Synthesis of zinc oxide nanoparticles with controlled morphology," Journal of Materials Chemistry, vol. 9, no. 11, pp. 2871-2878, 1999.

[10] J. E. Rodríguez-Paéz, A. C. Caballero, M. Villegas, C. Moure, P. Durán, and J. F. Fernández, "Controlled precipitation methods: formation mechanism of $\mathrm{ZnO}$ nanoparticles," Journal of the European Ceramic Society, vol. 21, no. 7, pp. 925-930, 2001.

[11] V. Khrenov, M. Klapper, M. Koch, and K. Müllen, "Surface functionalized $\mathrm{ZnO}$ particles designed for the use in transparent nanocomposites," Macromolecular Chemistry and Physics, vol. 206, no. 1, pp. 95-101, 2005.

[12] I. A. Toutorski, T. E. Tkachenko, B. V. Pokidko, N. I. Maliavski, and V. I. Sidorov, "Mechanical properties and structure of zinccontaining latex-silicate composites," Journal of Sol-Gel Science and Technology, vol. 26, no. 1-3, pp. 505-509, 2003.

[13] M. Purica, E. Budianu, E. Rusu, M. Danila, and R. Gavrila, "Optical and structural investigation of $\mathrm{ZnO}$ thin films prepared by chemical vapor deposition (CVD)," Thin Solid Films, vol. 403-404, pp. 485-488, 2002.

[14] N. Audebrand, J.-P. Auffrédic, and D. Louër, "X-ray diffraction study of the early stages of the growth of nanoscale zinc oxide crystallites obtained from thermal decomposition of four precursors. General concepts on precursor dependent micro structural properties," Chemistry of Materials, vol. 10, no. 9, pp. 2450-2461, 1998.

[15] Y. Yang, H. Chen, B. Zhao, and X. Bao, "Size control of ZnO nanoparticles via thermal decomposition of zinc acetate coated on organic additives," Journal of Crystal Growth, vol. 263, no. 1-4, pp. 447-453, 2004.

[16] D. Polsongkram, P. Chamninok, S. Pukird et al., "Effect of synthesis conditions on the growth of $\mathrm{ZnO}$ nanorods via hydrothermal method," Physica B, vol. 403, no. 19-20, pp. 3713-3717, 2008.

[17] C.-H. Lu and C.-H. Yeh, "Influence of hydrothermal conditions on the morphology and particle size of zinc oxide powder," Ceramics International, vol. 26, no. 4, pp. 351-357, 2000.

[18] Y. Zhu and Y. Zhou, "Preparation of pure $\mathrm{ZnO}$ nanoparticles by a simple solid-state reaction method," Applied Physics A, vol. 92, no. 2, pp. 275-278, 2008.

[19] T. Tani, L. Mädler, and S. E. Pratsinis, "Homogeneous ZnO nanoparticles by flame spray pyrolysis," Journal of Nanoparticle Research, vol. 4, no. 4, pp. 337-343, 2002.

[20] S. Jebril, H. Kuhlmann, S. Müller et al., "Epitactically interpenetrated high quality $\mathrm{ZnO}$ nanostructured junctions on microchips grown by the vapor-liquid-solid method," Crystal Growth and Design, vol. 10, no. 7, pp. 2842-2846, 2010.

[21] M. Singhal, V. Chhabra, P. Kang, and D. O. Shah, "Synthesis of $\mathrm{ZnO}$ nanoparticles for varistor application using $\mathrm{Zn}$-substituted aerosol OT microemulsion," Materials Research Bulletin, vol. 32, no. 2, pp. 239-247, 1997.

[22] B. P. Lim, J. Wang, S. C. Ng, C. H. Chew, and L. M. Gan, "A bicontinuous microemulsion route to zinc oxide powder," Ceramics International, vol. 24, no. 3, pp. 205-209, 1998.

[23] M. Inoguchi, K. Suzuki, K. Kageyama, H. Takagi, and Y. Sakabe, "Monodispersed and well-crystallized zinc oxide nanoparticles fabricated by microemulsion method," Journal of the American Ceramic Society, vol. 91, no. 12, pp. 3850-3855, 2008.

[24] S. Hingorani, V. Pillai, P. Kumar, M. S. Multani, and D. O. Shah, "Microemulsion mediated synthesis of zinc-oxide nanoparticles for varistor studies," Materials Research Bulletin, vol. 28, no. 12, pp. 1303-1310, 1993. 
[25] S. Hingorani, D. O. Shah, and M. S. Multani, "Effect of process variables on the grain growth and microstructure of $\mathrm{ZnO}$ $\mathrm{Bi}_{2} \mathrm{O}_{3}$ varistors and their nanosize $\mathrm{ZnO}$ precursors," Journal of Materials Research, vol. 10, no. 2, pp. 461-467, 1995.

[26] X. D. Gao, X. M. Li, and W. D. Yu, "Structural and morphological evolution of $\mathrm{ZnO}$ cluster film prepared by the ultrasonic irradiation assisted solution route," Thin Solid Films, vol. 484, no. 1-2, pp. 160-164, 2005.

[27] K.-K. Kim, H.-S. Kim, D.-K. Hwang, J.-H. Lim, and S.-J. Park, "Realization of p-type $\mathrm{ZnO}$ thin films via phosphorus doping and thermal activation of the dopant," Applied Physics Letters, vol. 83, no. 1, pp. 63-65, 2003.

[28] K. Y. Gao, T. Seyller, L. Ley et al., " $\mathrm{Al}_{2} \mathrm{O}_{3}$ prepared by atomic layer deposition as gate dielectric on $6 \mathrm{H}-\mathrm{SiC}(0001)$," Applied Physics Letters, vol. 83, no. 9, pp. 1830-1832, 2003.

[29] D. C. Look, G. M. Renlund, R. H. Burgener II, and J. R. Sizelove, "As-doped p-type $\mathrm{ZnO}$ produced by an evaporation/sputtering process," Applied Physics Letters, vol. 85, no. 22, article 3, pp. 5269-5271, 2004.

[30] Y. J. Zeng, Z. Z. Ye, W. Z. Xu et al., "Dopant source choice for formation of p -type ZnO: Li acceptor," Applied Physics Letters, vol. 88, no. 6, Article ID 062107, 2006.

[31] S. Limpijumnong, S. B. Zhang, S.-H. Wei, and C. H. Park, "Doping by large-size-mismatched impurities: the microscopic origin of arsenicor antimony-doped p-type zinc oxide," Physical Review Letters, vol. 92, no. 15, Article ID 155504, 2004.

[32] X. Pan, Z. Ye, J. Li et al., "Fabrication of Sb-doped p-type ZnO thin films by pulsed laser deposition," Applied Surface Science, vol. 253, no. 11, pp. 5067-5069, 2007.

[33] F. X. Xiu, Z. Yang, L. J. Mandalapu, D. T. Zhao, J. L. Liu, and W. P. Beyermann, "High-mobility Sb-doped p-type $\mathrm{ZnO}$ by molecular-beam epitaxy," Applied Physics Letters, vol. 87, no. 15, Article ID 152101, 3 pages, 2005.

[34] F. X. Xiu, Z. Yang, L. J. Mandalapu, D. T. Zhao, and J. L. Liu, "Photoluminescence study of Sb-doped $\mathrm{p}$-type $\mathrm{ZnO}$ films by molecular-beam epitaxy," Applied Physics Letters, vol. 87, no. 25, Article ID 252102, 3 pages, 2005.

[35] R. Chauhan, A. Kumar, and R. P. Chaudhary, "Synthesis and characterization of silver doped $\mathrm{ZnO}$ nanoparticles," Archives of Applied Science Research, vol. 2, no. 5, pp. 378-385, 2010.

[36] O. Lupan, L. Chow, L. K. Ono et al., "Synthesis and characterization of ag- or sb-doped zno nanorods by a facile hydrothermal route," Journal of Physical Chemistry C, vol. 114, no. 29, pp. 12401-12408, 2010.

[37] C. X. Mei, J. Yong, G. X. Yong, and Z. X. Wei, "Ag-doped ZnO nanorods synthesized by two-step method," Chinese Physics $B$, vol. 11, no. 21, Article ID 116801, 2012.

[38] M. Mahanti and D. Basak, "Ag-ZnO nanorods having enhanced emission and photocurrent properties," AIP Conference Proceedings, vol. 1447, pp. 713-714, 2011.

[39] Y. Zhang and J. Mu, "One-pot synthesis, photoluminescence, and photocatalysis of Ag/ZnO composites," Journal of Colloid and Interface Science, vol. 309, no. 2, pp. 478-484, 2007.

[40] V. G. Pol, A. Gedanken, and J. Calderon-Moreno, "Deposition of gold nanoparticles on silica spheres: a sonochemical approach," Chemistry of Materials, vol. 15, no. 5, pp. 1111-1118, 2003.

[41] K. Singh, S. Kumar, N. K. Verma, and H. S. Bhatti, "Photoluminescence properties of $\mathrm{Eu}^{3+}$-doped $\mathrm{Cd}_{1-x} \mathrm{Zn}_{x}$ S quantum dots,"
Journal of Nanoparticle Research, vol. 11, no. 4, pp. 1017-1021, 2009.

[42] Z. Li, Y. Ding, Y. Xiong, Q. Yang, and Y. Xie, "Room-temperature surface-erosion route to $\mathrm{ZnO}$ nanorod arrays and urchinlike assemblies," Chemistry, vol. 10, no. 22, pp. 5823-5828, 2004.

[43] U. Pal and P. Santiago, "Controlling the morphology of $\mathrm{ZnO}$ nanostructures in a low-temperature hydrothermal process," Journal of Physical Chemistry B, vol. 109, no. 32, pp. 15317-15321, 2005.

[44] Y. Zheng, C. Chen, Y. Zhan et al., "Photocatalytic activity of Ag/ $\mathrm{ZnO}$ heterostructure nanocatalyst: correlation between structure and property," Journal of Physical Chemistry C, vol. 112, no. 29, pp. 10773-10777, 2008.

[45] Y. J. Kwon, K. H. Kim, C. S. Lim, and K. B. Shim, "Characterization of $\mathrm{ZnO}$ nanopowders synthesized by the polymerized complex method via an organochemical route," Journal of Ceramic Processing Research, vol. 3, no. 3, pp. 146-149, 2002.

[46] R. F. Silva and M. E. D. Zaniquelli, "Morphology of nanometric size particulate aluminium-doped zinc oxide films," Colloids and Surfaces A, vol. 198-200, pp. 551-558, 2002.

[47] H. Li, J. Wang, H. Liu et al., "Sol-Gel preparation of transparent zinc oxide films with highly preferential crystal orientation," Vacuum, vol. 77, no. 1, pp. 57-62, 2004.

[48] S. Kurien, S. Sebastian, J. Mathew, and K. C. George, "Structural and electrical properties of nano-sized magnesium aluminate," Indian Journal of Pure and Applied Physics, vol. 42, no. 12, pp. 926-933, 2004.

[49] B. S. R. Devi, R. Raveendran, and A. V. Vaidyan, "Synthesis and characterization of $\mathrm{Mn}^{2+}$-doped $\mathrm{ZnS}$ nanoparticles," Pramana, vol. 68, no. 4, pp. 679-687, 2007.

[50] S. Suwanboon, "Structural and optical properties of nanocrystalline $\mathrm{ZnO}$ powder from sol-gel method," ScienceAsia, vol. 34, no. 1, pp. 31-34, 2008.

[51] A. H. Shah, E. Manikandan, M. Basheer Ahmed, and V. Ganesan, "Enhanced bioactivity of $\mathrm{Ag} / \mathrm{ZnO}$ nanorods-A comparative antibacterial Study," Journal of Nanomedicine \& Nanotechnology, vol. 4, no. 3, pp. 2-6, 2013.

[52] D. Sahu, B. S. Acharya, and A. K. Panda, "Role of Ag ions on the structural evolution of nano $\mathrm{ZnO}$ clusters synthesized through ultrasonication and their optical properties," Ultrasonics Sonochemistry, vol. 18, no. 2, pp. 601-607, 2011.

[53] H. Karami and E. Fakoori, "Synthesis and characterization of $\mathrm{ZnO}$ nanorods based on a new gel pyrolysis method," Journal of Nanomaterials, vol. 2011, Article ID 628203, 11 pages, 2011.

[54] Y. Ni, X. Cao, G. Wu, G. Hu, Z. Yang, and X. Wei, "Preparation, characterization and property study of zinc oxide nanoparticles via a simple solution-combusting method," Nanotechnology, vol. 18, no. 15, Article ID 155603, 2007.

[55] E. A. Meulenkamp, "Synthesis and growth of $\mathrm{ZnO}$ nanoparticles," Journal of Physical Chemistry B, vol. 102, no. 29, pp. 5566$5572,1998$.

[56] Y. W. Koh, M. Lin, C. K. Tan, Y. L. Foo, and K. P. Loh, "Selfassembly and selected area growth of zinc oxide nanorods on any surface promoted by an aluminum precoat," Journal of Physical Chemistry B, vol. 108, no. 31, pp. 11419-11425, 2004.

[57] H. Zhang, D. Yang, Y. Ji, X. Ma, J. Xu, and D. Que, "Low temperature synthesis of flowerlike zno nanostructures by cetyltrimethylammonium bromide-assisted hydrothermal process," Journal of Physical Chemistry B, vol. 108, no. 13, pp. 39553958, 2004. 
[58] S. López-Cuenca, L. A. Pérez Carrillo, M. Rabelero Velasco et al., "High-yield synthesis of zinc oxide nanoparticles from bicontinuous microemulsions," Journal of Nanomaterials, vol. 2011, Article ID 431382, 6 pages, 2011.

[59] K. Nejati, Z. Rezvani, and R. Pakizevand, "Synthesis of ZnO nanoparticles and investigation of the ionic template effect on their size and shape," International Nano Letters, vol. 1, no. 2, pp. 75-81, 2011. 

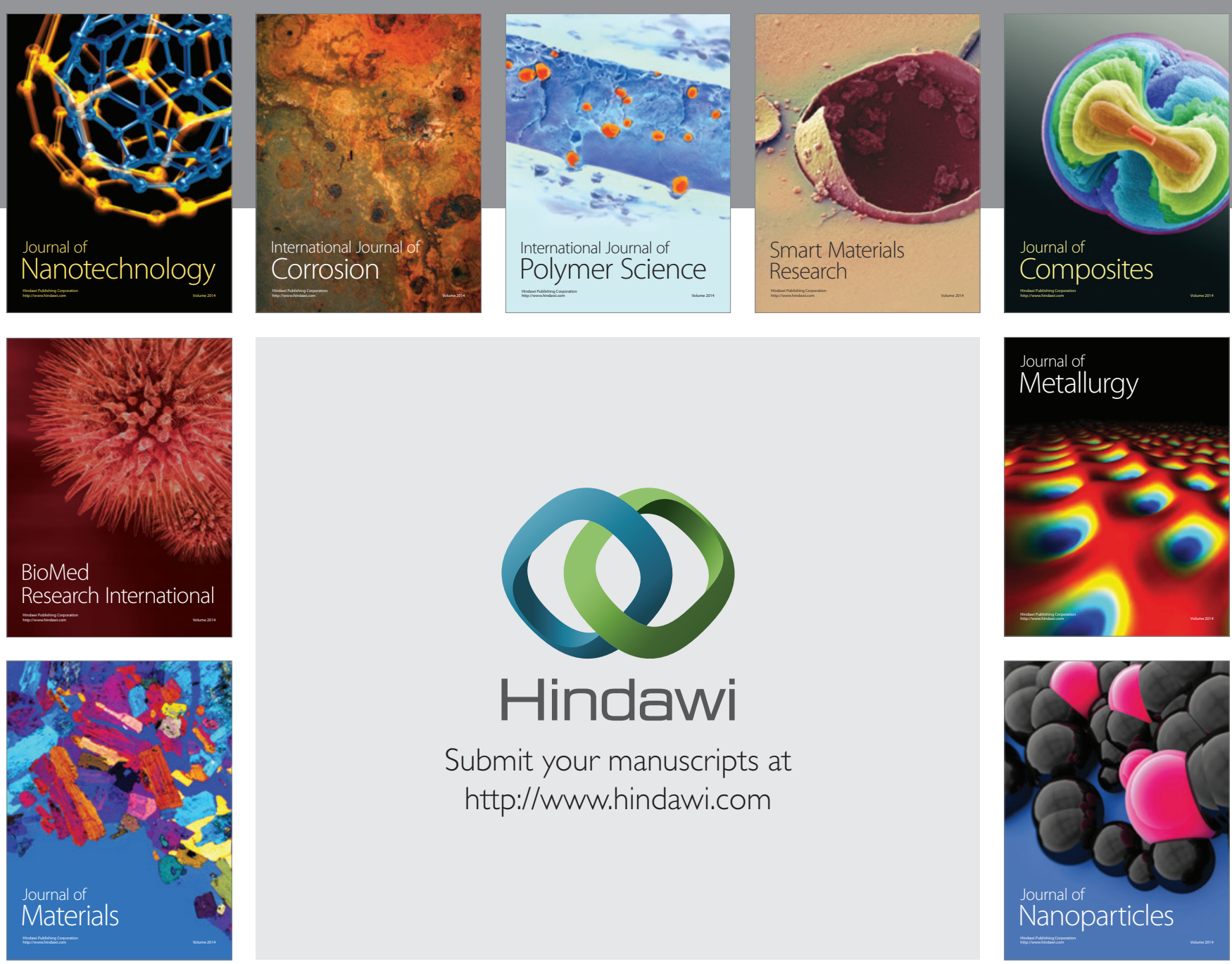

Submit your manuscripts at http://www.hindawi.com
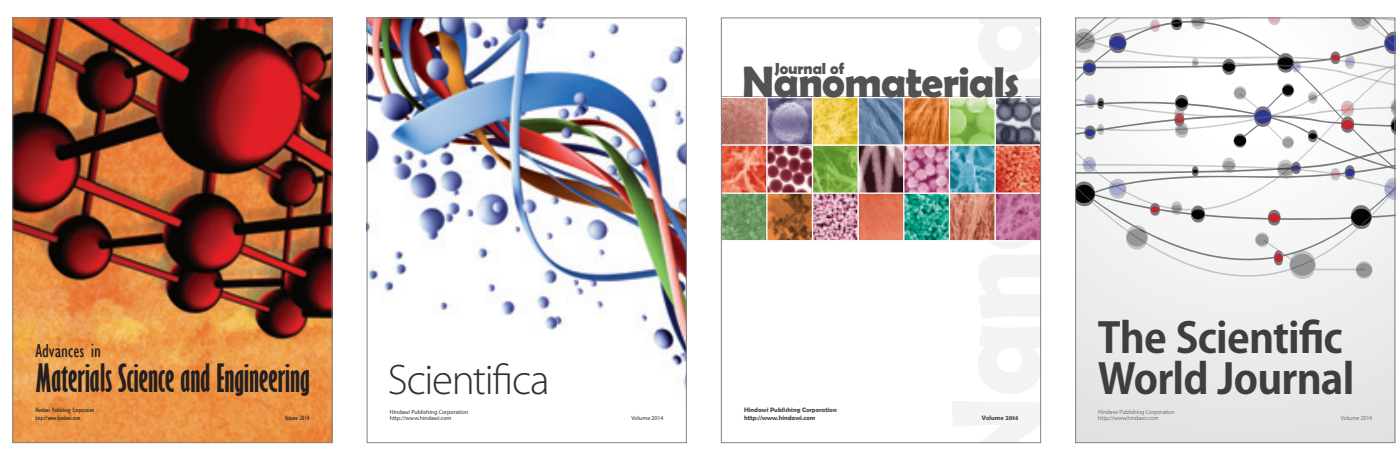

\section{The Scientific World Journal}
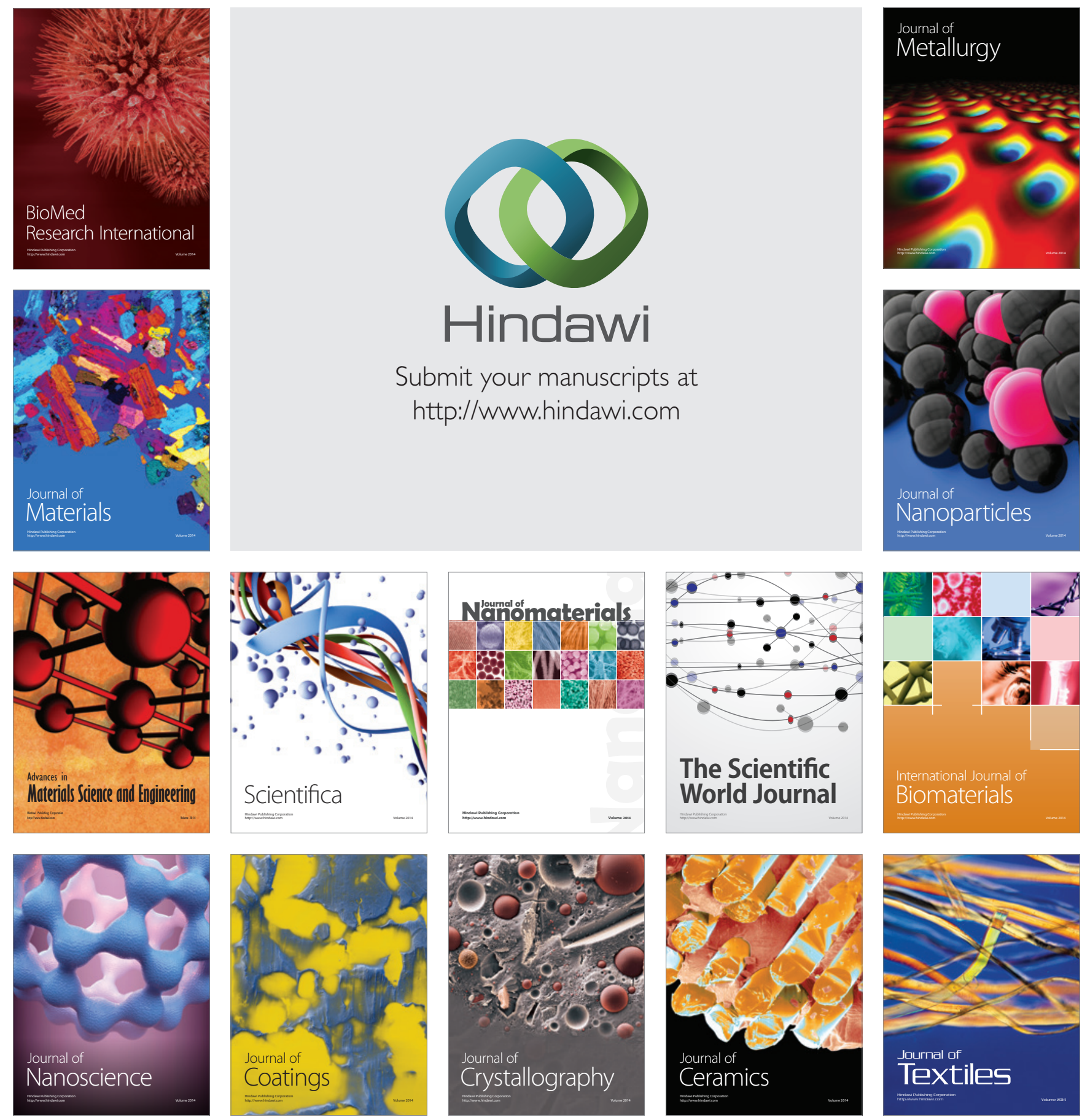